\title{
Type I Renal Tubular Acidosis
}

National Cancer Institute

\section{Source}

National Cancer Institute. Type I Renal Tubular Acidosis. NCI Thesaurus. Code C123220.

Impairment in renal collecting tubule acid secretion that results in a hypokalemic

hyperchloremic metabolic acidosis. 